\title{
ENERGY LEVELS OF LIGHT NUCLEI. III
}

\author{
$\mathbb{Z}=11$ to $\mathbb{Z}=20$ \\ P. M. ENDT and C. VAN DER LEUN \\ Fysisch Laboratorium der Rijksuniversiteit, Utrecht
}

\begin{abstract}
ADDENDA
By courtesy of the Editor these addenda, containing short references to material received in the period October 1, 1961-February 15, 1962, could be published together with the review article. In this way it was possible to shorten the period between the deadline and the date of publication appreciably. The data given in the addenda are not incorporated in the figures and master tables of the main text.
\end{abstract}

${ }^{21} \mathrm{Na}$

${ }^{20} \mathrm{Ne}(\mathrm{d}, \mathrm{n})^{21} \mathrm{Na}$

Analysis of the angular distribution measurements in Gr 61 yields reduced widths for groups (0) and (1) ${ }^{29}$. Analysis of the angular distributions reported in $\mathrm{Aj} 61$ yields $l_{\mathrm{p}}=2,4,0,0,1,1$, and 1 , and $(2 J+1) \theta_{\mathrm{p}}{ }^{2}=0.12,0.2,0.77$, $0.04,0.18,0.11$, and 0.25 for transitions to ${ }^{21} \mathrm{Na}^{*}=0+0.34,1.72,2.42,2.81$, $4.17+4.31,4.44+4.48$, and $5.00 \mathrm{MeV}$, respectively ${ }^{1}$.

\section{${ }^{22} \mathrm{Na}$}

${ }^{22} \mathrm{Na}\left(\beta^{-}\right)^{22} \mathrm{Ne}$

Deviation of the spectrum from the statistical shape is theoretically discussed ${ }^{10:}$.

\section{${ }^{23} \mathrm{Na}$}

${ }^{20} \mathrm{Ne}(\alpha, \mathrm{p})^{23} \mathrm{Na}$

At $E_{\alpha}=27 \mathrm{MeV}$, angular distributions of groups $(0+1)$ and $(2+3+1+$ $5+6$ ) have been measured ${ }^{79}$. 


$$
{ }^{22} \mathrm{Ne}(\mathrm{d}, \mathbf{n})^{23} \mathrm{Na}
$$

Besides the groups already mentioned in Gr 61 , groups have also been observed to ${ }^{23} \mathrm{Na}$ states at $E_{\mathrm{x}}=3.90 \pm 0.10,4.45 \pm 0.20,4.75 \pm 0.15$, and $5.16 \pm 0.10$ Mel'29.

$$
{ }^{23} \mathrm{Ye}\left(\beta^{-}\right)^{23 \mathrm{Na}}
$$

The recoil energy spectrum agrees to within $1 \%$ with the supposition that the $\beta^{-}$transitions to ${ }^{23} \mathrm{Na}(0)$ and (1) both have pure axial vector character ${ }^{16}$.

$$
{ }^{23} \mathrm{Na}(\gamma, \gamma)^{23} \mathrm{Na}
$$

The mean life of ${ }^{23} \mathrm{Na}(1)$ has been measured as $(1.88 \pm 0.25) \times 10^{-12} \mathrm{sec}$ in a bremsstrahlung resonance fluorescence experiment ${ }^{50}$. An analogous experiment vields the mean life of the $2.98 \mathrm{MeV}$ level ${ }^{8}$.

${ }^{23} \mathrm{Na}\left(\mathrm{n}, \mathrm{n}^{\prime}\right)^{23} \mathrm{Na}$

Cross section at $E_{\mathrm{a}}=14 \mathrm{MeV}^{86}$.

${ }^{23} \mathrm{Na}\left(\mathrm{p}, \mathrm{p}^{\prime}\right){ }^{23} \mathrm{Na}$

Theoretical discussion of anomalies in the cross section for Coulomb excitation ${ }^{8 \%}$.

$$
\because \operatorname{Mg}(\gamma, \mathrm{p})^{23 \mathrm{Na}}
$$

Angular aistributions of photo-protons from deformed nuclei have been computed ${ }^{30}$.

$$
24 \mathrm{Na}(\beta-)^{24} \mathrm{Mg}
$$

$$
24 \mathrm{Na}
$$

A half-life measurement yields $15.05 \pm 0.03 \mathrm{hr} 44$. The $\beta$ - spectrum between 300 and $1300 \mathrm{keV}$ has the allowed shape within $0.5 \%{ }^{23}$. An angular correlation measurement of the 2.75 and $1.37 \mathrm{MeV} \gamma$ rays shows that both are pure $\mathrm{E} 2$, with an $\mathrm{M} S$ admixture in the former of at most $0.003 \%{ }^{26}$. A precision measurement of the energy of the ${ }^{24} \mathrm{Mg}(1) \rightarrow(0)$ transition yields $E_{\gamma}=1368.41 \pm 0.20 \mathrm{keV}$ (after Doppler correction) ${ }^{31}$.

${ }^{23} \mathrm{Na}(\mathrm{d}, \mathrm{p})^{24} \mathrm{Na}$

At $E_{\mathrm{d}}=8.9 \mathrm{MeV}$, excitation energies of many ${ }^{23} \mathrm{Na}$ levels up to $E_{\mathrm{x}}=\mathbf{5 . 4 2}$ $\| \in V, l_{n}$ values, and relative reduced widths have been measured ${ }^{20}$.

$$
\because \mathbb{1}(n, \alpha)^{24)}, \mathrm{a}
$$

T.ut in al cross section has been measurad in the $E_{n}=12.0-19.6 \mathrm{MeV}$ region .

$$
{ }^{16} \mathrm{O}\left({ }^{12} \mathrm{C}, \alpha\right)^{24} \mathrm{Mg}
$$

Alpha-particle angular distributions in the neighbourhood of $\vartheta=0^{\circ}$ yield 
even parity for all ${ }^{24} \mathrm{Mg}$ states up to and including that at $E_{\mathrm{x}}=6.43 \mathrm{Mel}$. ${ }^{20} \mathrm{Ne}(\alpha, \gamma)^{24} \mathrm{Mg}$

The following resonances have been found (with $f^{\pi}$ values from angular distribution measurements): $E_{\alpha}=1.630,1.916(2+), 2.029(2+), 2.212,2.273$, all \pm 0.015 , and $2.489\left(1^{-}\right), 2.564\left(2^{+}\right), 2.643(2+), 2.358,2.898,3.060\left(1^{-}\right)$, and $3.190 \mathrm{MeV}$, all $\pm 0.010 \mathrm{MeV}$, corresponding to ${ }^{24} \mathrm{Mg}$ levels at $E_{\mathrm{x}}=10.60^{2} \mathrm{~b}$ : $10.911^{\mathrm{b}}, 11.004^{\mathrm{b}}, 11.157,11.208,11.398^{\mathrm{a} . \mathrm{b}}, 11.450^{\mathrm{a}, \mathrm{b}}, 11.516^{\mathrm{a}, \mathrm{b}}, 11.696$, $11.729^{a}, 11.863^{\mathrm{a}, \mathrm{b}}$, and $11.972^{\mathrm{a}, \mathrm{c}} \mathrm{MeV}$, respectively. The levels markeda, marked $^{b}$, and ${ }^{c}$, were known from the ${ }^{20} \mathrm{Ne}(\alpha, \alpha)^{20} \mathrm{Ne},{ }^{23} \mathrm{Na}\left({ }^{3} \mathrm{He}, \mathrm{d}\right)^{24} \mathrm{Mg}$, and ${ }^{23} \mathrm{Na}\left(\mathrm{p}, \alpha_{0}\right)^{20} \mathrm{Ne}$ reactions, respectively ${ }^{88}$.

${ }^{23} \mathrm{Na}(\mathrm{p}, \gamma){ }^{24} \mathrm{Mg}$

Gamma-ray branchings and "y values have been measured at twelve resonances in the $E_{\mathrm{p}}=594-1419 \mathrm{keV}$ region. The ${ }^{24} \mathrm{Mg}$ levels at $4.23,7.35$, 7.62 , and $7.75 \mathrm{MeV}$ have $\Gamma_{\gamma_{0}} / \Gamma_{;_{1}}=2.7,1.5,0.67$, and 0.67 , respectively ${ }^{61}$.

${ }^{23} \mathrm{Na}(\mathrm{p}, \alpha)^{20} \mathrm{Ne}$

Yields and total widths have been measured of resonances in the $E_{\mathrm{p}}=200$ $450 \mathrm{keV}$ region. From angular distribution measurements, spins and parities are assigned to three resonances ${ }^{25}$.

$24 \mathrm{Mg}(\gamma, \gamma)^{24} \mathrm{Mg}$

Betatron bremsstrahlung excites three levels in ${ }^{24} \mathrm{Mg}$, at $8,9.3$, and 10.2 $\mathrm{MeV}$, with $\Gamma_{\gamma}=0.5,0.9$, and $3.8 \pm 1.2 \mathrm{eV}$, respectively ${ }^{71}$. An analogous experiment yields the excitation of states at 9.9 and $10.8 \mathrm{MeV}^{2}$.

$24 \mathrm{Mg}(\mathrm{n}, \mathrm{n})^{24} \mathrm{lg}$

The azimuthal asymmetry in elastic scattering has been measured of partially polarized neutrons at $E_{\mathrm{n}}=0.2-0.7 \mathrm{MeV}^{42}$ and $E_{\mathrm{n}}=2.8 \mathrm{MeV}^{36}$.

${ }^{24} \mathrm{Mg}\left(\mathrm{p}, \mathrm{p}^{\prime}\right)^{24} \mathrm{Mg}$

Angular distributions of groups (0) and (1) have been measured at several proton energies in the $E_{\mathrm{p}}=7-16 \mathrm{MeV}$ region ${ }^{4.5}$. The azimuthal asymmetry in elastic scattering has been observed of partially polarized $8 \mathrm{MeV}$ protons ${ }^{64}$.

In the main text of this review paper, erroneously no mention has been made of a measurement of the excitation of ${ }^{24} \mathrm{Mg}(6): 6.432 \pm 0.010 \mathrm{MeV}$ (Co 61d).

$$
{ }^{24} \mathrm{Mg}\left(\alpha, \alpha^{\prime}\right)^{24} \mathrm{Mg}
$$

At $E_{\alpha}=42 \mathrm{MeV}$, inelastic scattering angulat disiributions have been measured corresponding to $E_{\mathrm{x}}=4.12,4.23,6.0$, and $6.4 \mathrm{MeV}$ levels ${ }^{82}$.

${ }^{27} \mathrm{Al}(\mathrm{p}, \alpha)^{24} \mathrm{Mg}$

The ground-state $Q$ value has been measured c.s $1.598 \pm 0.003 \mathrm{MeV}^{24}$. Angular 
distributions of $\alpha_{0}$ and $\alpha_{1}$ have been obtained at $E_{\mathrm{p}}=10.0,10.5,11.0,11.5$, and $12.0 \mathrm{MeV}$.

\section{REMARKS}

The fine structure in the $(\gamma, p)$ and $(\gamma, n)$ cross sections on ${ }^{24} \mathrm{Mg}$ is computed ${ }^{58}$. Shell model calculations yield energy levels and branching ratios in ${ }^{24} \mathbf{M g}^{28}$. Application of the random-phase approximation to the giant $\mathrm{E} 1$ resonance of ${ }^{24} \mathrm{Mg}$ yields two well separated peaks ${ }^{108}$.

${ }^{24} \mathrm{Mg}(\mathrm{d}, \mathrm{p})^{25} \mathrm{Mg}$

\section{${ }^{25} \mathrm{Mg}$}

From the angular distribution measurements in $\mathrm{Mi} 61 \mathrm{a}, l_{\mathrm{n}}$ values an 1 reduced widths are extracted by D.W.B.A. analysis ${ }^{15}$. Comparison of the results of Hi $61 \mathrm{~h}$ and $\mathrm{Ja} 61 \mathrm{a}$ indicates that several of the groups leading to levels given in table 25.9 , coltumn 1 ( $\mathrm{Ja} 61 \mathrm{a}$ ), have erroneous!y been ascribed to ${ }^{25} \mathrm{Mg}$. Correction yields only the following ${ }^{25} \mathrm{Mg}$ levels: $4.727,5.020,5.123,5.252,5.479$, and $5.508 \mathrm{MeV}$, all $\pm 0.004 \mathrm{MeV}^{102}$.

${ }^{27} \mathrm{Al}(\gamma, \mathrm{d}){ }^{25} \mathrm{Mg}$

Yield maasurement $\left(E_{\max }=35 \mathrm{MeV}\right)$ and comparison of $(\gamma, \mathrm{d})$ and $(\gamma, \mathrm{p})$ yields ${ }^{89}$.

${ }^{2 i} \mathrm{Al}(\mathrm{n}, \mathrm{t}){ }^{25 \mathrm{Mg}}$

The cross section has been measured for fission neutrons ${ }^{\mathbf{3 3}}$.

${ }^{27} \mathrm{Al}(\mathrm{d}, \alpha)^{25} \mathrm{Mg}$

Excitation energies are given of 66 levels in ${ }^{25} \mathrm{Mg}$ with $2-10 \mathrm{keV}$ errors; $Q_{r}=6.690 \pm 0.011 \mathrm{MeV}^{69}$. A statistical model discussion of the $(2 J+1)$ intensity rule is given ${ }^{106}$.

${ }^{28} \mathrm{Si}(\mathrm{n}, \propto)^{25} \mathrm{Mg}$

In the $\mathbb{E}_{\mathrm{n}}=4.6-8.6 \mathrm{MeV}$ region, strong resonance structure has been observed in the yield of groups $\alpha_{0}$ through $\alpha_{4}{ }^{10}$.

\section{REMARKS}

Fine structure in $(\gamma, \mathrm{p})$ and $(\gamma, \mathrm{n})$ yields on ${ }^{25} \mathrm{Mg}$ has been computed ${ }^{58}$. The $\alpha$-particle model has been applied to a description of the ${ }^{25} \mathrm{Mg}-{ }^{25} \mathrm{Al}$ level schern... $\mathrm{s}^{53}$

$$
{ }^{25} \mathrm{Mg}(\mathrm{d}, \mathrm{p})^{26 \mathrm{Mg}}
$$

In the $E_{\mathrm{d}}=1.5-3.0 \mathrm{MeV}$ region, angular distributions and exitation functions have been measured of groups $\mathrm{p}_{\mathbb{1}}$ and $\mathrm{p}_{2}{ }^{73}$. 
${ }^{27} \mathrm{Al}(\gamma, \mathrm{p})^{26} \mathrm{Mg}$

Proton spectra and angular distributions have been measured at $E .=17.6$ $\mathrm{MeV}^{12}$, and with bremsstrahlung of $E_{\max }=21 \mathrm{MeV}^{48}$. Yield meastrements with $E_{\max }=35 \mathrm{MeV}^{89}$.

${ }^{27} \mathrm{Al}\left({ }^{16} \mathrm{O},{ }^{17} \mathrm{~F}\right){ }^{26} \mathrm{Mg}$

The cross section has been measured at $E\left({ }^{16} C^{\prime}\right)=36 \mathrm{MeV}^{90}$.

${ }^{25} \mathrm{Mg}(\mathrm{p}, \gamma){ }^{26} \mathrm{Al}$

\section{${ }^{26} \mathrm{Al}$}

In the $E_{\mathrm{p}}=0.9-1.8 \mathrm{MeV}$ region, 33 resonances have been observed. The $y$-ray branching of 20 resonances and of 24 low $r$ levels is given. The $2.08 \mathrm{MeV}$ level is shown to be a doublet ${ }^{57}$.

$$
{ }^{27} \mathrm{Al}\left({ }^{16} \mathrm{O},{ }^{16} \mathrm{~F}\right){ }^{27} \mathrm{Mg}
$$

${ }^{27} \mathbf{M g}$

The cross section has been measured at $E^{16}()_{1}=36 \mathrm{MeV}^{90}$.

${ }^{24} \mathrm{Mg}(\alpha, \mathrm{p})^{27} \mathrm{Al}$

${ }^{27} \mathrm{Al}$

The ground-state $Q$ value is measured as $-1598 \pm 0.005 \mathrm{MeV}^{24}$.

${ }^{26} \mathrm{Mg}(\mathrm{p}, \gamma)^{27} \mathrm{Al}$

The $\gamma$-brinching of the $E_{\mathrm{p}}=721,809,839$, an $1954 \mathrm{keV}$ resonances has been measured. Spins, parities, and mixing ratios were obtained from angular distribution and correlation measurements ${ }^{59}$.

${ }^{27} \mathrm{Al}(\gamma, \gamma){ }^{27} \mathrm{Al}$

From a bremsstrahlung resonance fluorescerce experiment the mean life has been obtained of the $E_{\mathrm{x}}=2.98+3.00 \mathrm{MV}$ doublet (unresolved) ${ }^{8}$. The yield curve of resonantly scattered bremsstra ung with an energy between $E_{\max }$ and $E_{\max }-1 \mathrm{MeV}$ shows a peak at $8.3 \mathrm{Mi}^{2} \mathrm{~V}^{74}$. Bremsstrahlung resonant scattering shows the giant resonance to be do uble; the angular disiribution is consistent with dipole scattering ${ }^{13}$.

${ }^{27} \mathrm{Al}(\mathrm{n}, \mathrm{n})^{27} \mathrm{Al}$

The azimuthal asymmetry in elastic scatter $1 \mathrm{~g}$ has been measured of partially polarized neutrons at $E_{\mathrm{n}}=2.8 \mathrm{MeV}^{36},$. nd at $E_{\mathrm{n}}=24 \mathrm{MeV}$. Elastic scattering differential cross section at $E_{\mathrm{n}}=: 4 \mathrm{MeV}^{54}$. Inelastic sca:tering cross section at $E_{\mathrm{n}}=14.3,15.4$, and $16.1 \mathrm{Me} \cdot{ }^{91}$.

${ }^{27} \mathrm{Al}\left(\mathrm{p}, \mathrm{p}^{\prime}\right)^{27} \mathrm{Al}$

Measurements have been performed of the lastic differential cross sectior 
at $6.8 \mathrm{MeV}^{62}$, of the azimuthal asymmetry in elastic scattering of $8 \mathrm{MeV}$ polarized protons ${ }^{64}$, of angular distributions of inelastically scattered protons $\left(E_{\mathrm{p}}=6.5-7.4 \mathrm{MeV}\right)^{39}$, and of energies of $\gamma$ rays resulting from inelastic scattering ${ }^{46}$. A theoretical discussion is given of the results in Jo $61 \mathrm{~b}^{65}$.

${ }^{27} \mathrm{Al}(\mathrm{d}, \mathrm{d}){ }^{27} \mathrm{Al}$

The elastic scattering differential cross section has been measured at $E_{\mathrm{d}}=11.8 \mathrm{MeV}^{22}$.

${ }^{27} \mathrm{Al}\left(\alpha, \alpha^{\prime}\right)^{27 \mathrm{Al}}$

At $E_{z} \approx 42 \mathrm{MeV}, \sigma(\vartheta)$ has been measured for $\alpha_{0}$ and for several inelastically scattered groups ${ }^{51,82}$.

${ }^{28 \mathrm{Si}}(\gamma, \mathrm{p})^{27} \mathrm{Al}$

The proton energy spectrum and $\sigma(\vartheta)$ has been measured of bremsstrahlung of $E_{\max }=24 \mathrm{MeV}^{68}$.

${ }^{28} \mathrm{Si}(\boldsymbol{\gamma}, \mathrm{n})^{27 \mathrm{Si}}$

${ }^{27} \mathrm{Si}$

Threshold sıleasurement yields $E_{\text {thresh }}=17.14 \pm 0.12 \mathrm{MeV}^{92}$ 。

${ }^{28} \mathrm{Mg}\left(\beta^{-}\right)^{28} \mathrm{Al}$

${ }^{28} \mathrm{Mg}$

The half-life is $21.2 \pm 0.1 \mathrm{hr}^{55}$.

${ }^{28} \mathrm{Al}\left(\beta^{-}\right)^{28} \mathrm{Si}$

The half-life is $2.26 \pm 0.01 \mathrm{~m}^{55}$.

${ }^{27} \mathrm{Al}\left({ }^{16} \mathrm{O},{ }^{15} \mathrm{O}\right){ }^{28} \mathrm{Al}$

At $E\left({ }^{16} \mathrm{O}\right)=36 \mathrm{MeV}$, the cross section $\sigma \leqslant 7 \mu \mathrm{b}^{\mathrm{n} 0}$.

$\left.{ }^{28} \mathrm{~S} ., \mathrm{n}, \mathrm{p}\right)^{28} \mathrm{Al}$

In the $E_{\mathrm{n}}=4.6-8.6 \mathrm{MeV}$ region, strong resonance structure has been observed in the yield of groups $\mathrm{p}_{0}$ through $\mathrm{p}_{9}{ }^{10}$.

${ }^{16} \mathrm{O}\left({ }^{16} \mathrm{~L}, \alpha\right){ }^{28} \mathrm{Si}$

${ }^{28} \mathrm{Si}$

A to and including that at $6.28 \mathrm{MeV}^{80}$.

${ }^{24} \mathrm{Mg}(\alpha, y)^{28 \mathrm{Si}}$

The following resonances $\left(E_{\alpha}\right.$ in $\left.\mathrm{MeV}\right)$ have been found (in brackets relative intensıties and $J \pi$ are given, the latter from angular distribution measurements) : $3.21\left(1.0 ; 2^{+}\right), 3.31\left(0.1 ; 0^{+}\right.$or $\left.4^{+}\right), 3.36\left(0.1 ; 4^{+}\right), 3.42\left(0.3 ; 4^{+}\right), 3.51(0.2 ; 1-)$, 
$3.59\left(0.1 ; 4^{+}\right), 3.66\left(0.9 ; 2^{+}\right), 3.82\left(0.2 ;\left(4^{+}\right)\right), 4.35\left(0.4 ; 2^{+}\right)^{9 \cdot 3}$. The resonance energies given in $\mathrm{Sm} 60 \mathrm{a}$ and $\mathrm{Sm} 61 \mathrm{a}$ have to be lowered by $0.28 \%$. A new resonance at $E_{\alpha}=2.932 \mathrm{MeV}$, corresponding to the ${ }^{27} \mathrm{Al}(\mathrm{p}, \gamma)^{28}$ Si resonance at $E_{\mathrm{p}}=936 \mathrm{keV}$ has $(2 J+1) \gamma=0.10 \mathrm{eV} 88$.

${ }^{27} \mathrm{Al}(\mathrm{p}, \gamma)^{28 \mathrm{Si}}$

The "Lewis effect" was observed at the $E_{p}=992 \mathrm{keV}$ resonance; it may have caused errors in former precision energy measurements ${ }^{76}$.

The $\gamma$ decay of the $759,766,773$, and $993 \mathrm{keV}$ resonances has been investigated $^{93}$. The data given in reference $\mathrm{Va} 61 \mathrm{c}$ have been published ${ }^{85}$.

${ }^{28} \mathrm{Si}(\gamma, \gamma)^{28 \mathrm{Si}}$

The yield curve of resonantly scattered bremsstrahlung with an energy between $E_{\max }$ and $E_{\max }-1 \mathrm{MeV}$ show's peaks at 6, 10.4, and $12.0 \mathrm{MeV}$. In the spectrum of resonantly scattered bremsstrahlung peaks have been obseryed at $E_{\gamma}=9.8$ and $11.3 \mathrm{MeV}$, both correspondirg to breaks in the yield curve. These levels have $\Gamma_{i^{\prime}}=0.9$ and $8.3 \pm 2.5 \mathrm{eV}$, respectively ${ }^{11}$.

${ }^{28} \mathrm{Si}(\mathrm{d}, \mathrm{d})^{28} \mathrm{Si}$

Al $E_{\mathrm{d}}=11.5 \mathrm{MeV}, \sigma(\vartheta)$ has been measured for elast c scattering ${ }^{22}$.

${ }^{29} \mathrm{Si}(\gamma, \mathrm{n})^{28 \mathrm{Si}}$

The threshold has been measured as $8.47 \pm 0.07 \mathrm{MeV}^{92}$.

${ }^{29} \mathrm{Si}$

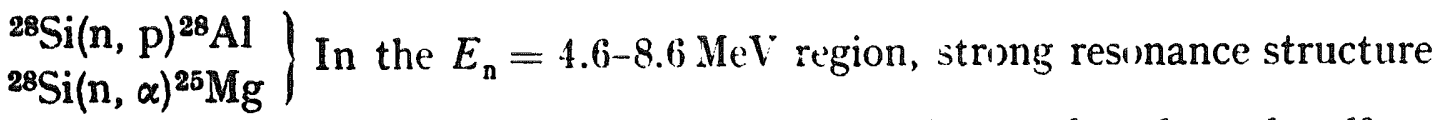
has been observed in the yield of groups $p_{0}$ through $p_{5}$ and $\alpha_{0}$ through $\alpha_{4}{ }^{10}$.

${ }^{29} \mathrm{Si}(\gamma, \gamma)^{29} \mathrm{Si}$

The mean life of the $2.43 \mathrm{MeV}$ level has been determined from bremsstrahlung resonance scattering ${ }^{8}$.

${ }^{29} \mathrm{Si}\left(\mathrm{p}, \mathrm{p}^{\prime}\right){ }^{29} \mathrm{Si}$

The angular distribution of the $1.28 \mathrm{MeV},{ }^{\prime}$ ray, excite 1 in inelastic scattering, has been computed ${ }^{72}$.

$$
{ }^{30} \mathrm{Si}(\gamma, n)^{29 S i}
$$

Threshold measurement yields $E_{\text {taresh }}=10.62 \pm 0.07 \mathrm{MeV}^{92}$.

\section{P}

${ }^{28} \mathrm{Si}(\mathrm{p}, \mathrm{p})^{28 \mathrm{Si}}$

Improved analysis of the experiments given in $\mathrm{Br} 6$ a yielcs an addition 4 ! resonance at $E_{\mathrm{p}}=6.60 \mathrm{MeV}$ with $\Gamma \approx 150 \mathrm{keV}$, and cliarges the $l_{\mathrm{p}}$ valurs of the following levels: ${ }^{29} \mathrm{P}^{*}=7.50\left(l_{\mathrm{p}}=2\right), 7.74(2), 7.32(3), 3.20(2), 8.2(i(1)$, $8.49((0)), 8.51(2), 8.62((1)), 8.89(2), 9.06(1), 9.28(1)$, and $9.37((2,1)) \mathrm{MeV}^{94}$ 
${ }^{27} \mathrm{Al}(\alpha, p)^{30 \mathrm{Si}}$

30 Si

At $E_{\alpha}=42 \mathrm{MeV}, \sigma(\vartheta)$ has been measured of several proton groups ${ }^{43}$.

$295 \mathrm{i}(\mathrm{d}, \mathrm{p})^{30 \mathrm{Si}}$

Angular distributions of the groups to ${ }^{30} \mathrm{Si}(0)$ and (1) yield $l_{\mathrm{n}}=0$ and 2 , respectively ${ }^{95}$.

$31 \mathrm{P}(\mathrm{y}, \mathrm{p})^{30 \mathrm{Si}}$

The proton energy spectrum and $\sigma(\mathscr{y})$ have been measured with bremsstrahlung of $E_{\max }=24 \mathrm{MeV}^{68}$.

${ }^{29} \mathrm{Si}(\mathrm{p}, \gamma)^{30 \mathrm{P}}$

\section{${ }^{30} \mathbb{P}$}

Angular distribution measurements at the $E_{\mathrm{p}}=1330 \mathrm{keV}$ resonance yield $j^{\pi}=2^{+}$and $T=1$ for the resonance level ${ }^{97}$. The results given in $\mathrm{Ba} 60 \mathrm{f}$ are discussed ${ }^{107}$.

${ }^{32} \mathrm{~S}(\mathrm{n}, \mathrm{t})^{30 \mathrm{P}}$

Cross section at $E_{\mathrm{n}}=14.7 \mathrm{MeV}, \sigma=20 \pm 5 \mu \mathrm{b}^{96}$.

${ }^{30 \mathrm{Si}}(\mathrm{p}, \gamma)^{31 \mathrm{P}}$

$31 \mathbb{P}$

Yields and $\gamma$-decay modes have been measured of resonances in the $E_{\mathrm{p}}=975$ $1840 \mathrm{keV}$ region. The $E_{\mathrm{x}}=4.26 \mathrm{MeV}$ level in ${ }^{31} \mathrm{P}$ mainly decays by a $\gamma_{0}$. An angular distribution measurement shows the $1480 \mathrm{keV}$ resonance to have $J^{r}=\frac{3}{2}+31$. Gamma-ray angular distribution and polarization measurements yield $J^{x}=\frac{3}{2}^{+}, \frac{3}{2}^{+}, \frac{3}{2}^{+}$, and $\frac{5}{2}+$, for the resonances at $773,939,979.5$, and 1393 $\mathrm{keV}$, respectively ${ }^{25}$.

${ }^{31} \mathrm{P}(\gamma, \gamma)^{31} \mathrm{P}$

The mean life of the 2.23 and $3.13 \mathrm{MeV}$ levels has been found from bremsstrahlung resonant fluorescence?, 8 .

${ }^{31} \mathrm{P}\left(\mathrm{p}, \mathrm{p}^{\prime}\right)^{31 \mathrm{P}}$

Angular distributiol ${ }^{5}$ have been measured of groups $\mathrm{p}_{1}$ and $\mathrm{p}_{2}$ in the $5=6.5-7.4 \mathrm{MeV}$ region ${ }^{39}$.

${ }^{31} \mathrm{P}(1 \mathrm{l}, \mathrm{d})^{3 \mathrm{IP}}$

At $E_{0}=11.5 \mathrm{MeV}, \sigma^{\prime}(2)_{\mathrm{elas}}$ has been measured ${ }^{22}$.

$32 \mathrm{~S}(\mathrm{y}, \mathrm{p})^{31 \mathrm{P}}$

The angular distribution has been obtained with bremsstrahlung of $E_{\max }=21$
$V$. MeVis. 


\section{${ }^{32} \mathrm{P}\left(\beta^{-}\right)^{32} \mathrm{~S}$}

The Kurie plot of the $\beta^{-}$spectrum shows deviations from linearity ${ }^{23}$. The $\log f t$ value and deviations from the allowed shape are theoretically discussed ${ }^{17}, 104$.

${ }^{28} \mathrm{Si}(\alpha, \gamma){ }^{32} \mathrm{~S}$

The resonance energies given in Sm 61 a have to be lowered by $0.28 \%{ }^{88}$.

${ }^{28} \mathrm{Si}(\alpha, \alpha)^{28} \mathrm{Si}$

The $\alpha_{0}$ yield measured at several angles in the $E_{\alpha}=3.0-5.3 \mathrm{MeV}$ range shows resonances at $E_{\alpha}=3.90,4.32,4.45$, and $4.72 \mathrm{MeV}$, corresponding to ${ }^{32} \mathrm{~S}$ levels at $10.33,10.70,10.81$, and $11.05 \mathrm{MeV}^{83}$.

${ }^{31} \mathrm{P}(\mathrm{p}, \gamma)^{32 \mathrm{~S}}$

Gamma decay and angular distribution me asurements yield $J^{n}=1^{+}$for the $E_{\mathrm{p}}=355$ and $440 \mathrm{keV}$ resonances ${ }^{56}$. This reference replaces Sc 61c. Precision measlirements yield the following values for the :esonance energies: $E_{\mathrm{p}}=354.6 \pm 0.4,439.1 \pm 0.5,541.1 \pm 0.6$, and $642.0 \pm 0.7 \mathrm{keV}^{98}$.

${ }^{31} \mathrm{P}(\mathrm{p}, \mathrm{p})^{31} \mathrm{P}$

In the $E_{\mathrm{p}}=1.2-1.9 \mathrm{MeV}$ region, five resonances thave been observed in $\sigma(\vartheta)_{\text {elast }}{ }^{18}$.

${ }^{31} \mathrm{P}\left({ }^{3} \mathrm{He}, \mathrm{d}\right){ }^{32} \mathrm{~S}$

At $E_{\mathrm{d}}=7 \mathrm{MeV}$, angular distribution measurements yield $l_{\mathrm{p}}=2$ and 0 , for groups $d_{1}$ and $d_{2}$, respectively ${ }^{34}$.

${ }^{32} \mathrm{~S}(\gamma, \gamma)^{32} \mathrm{~S}$

The yield curve of resonantly scattered bremsstrahlung with energies between $E_{\max }$ and $E_{\max }-1 \mathrm{MeV}$ shows a peak at $8.5 \mathrm{MeV}^{74}$.

${ }^{32} \mathrm{~S}\left(\mathrm{e}, \mathrm{e}^{\prime}\right)^{32} \mathrm{~S}$

Coulomb excitation of the $3.78 \mathrm{MeV}$ level in ${ }^{32} \mathrm{~S}$ indicates that the transition is certainly not E2, but perhaps E. $0^{84}$.

${ }^{32} \mathrm{~S}(\mathrm{n}, \mathrm{n})^{32} \mathrm{~S}$

At $E_{\mathrm{n}}=14 \mathrm{MeV}, \sigma(\vartheta)_{\text {elast }}$ has been measured ${ }^{70}$.

${ }^{32} \mathrm{~S}\left(\mathrm{p}, \mathrm{p}^{\prime}\right)^{32} \mathrm{~S}$

Several $\gamma$ transitions have been observed following inelastic proton scattering; no $\mathrm{e}^{+}-\mathrm{e}^{-}$pairs are seen de-exciting ${ }^{32} \mathrm{~S}(2)^{35}$. 
$32 S(d, d)^{32}=$

At $E_{\AA}=11.5 \mathrm{MeV}, o(i)_{\text {elast }}$ has been measured ${ }^{22}$.

$32 \varsigma(d, p)^{33} S$

$33 \mathrm{~S}$

At $E_{d}=8.9 \mathrm{MeV}$, excitation energies, $l_{\mathrm{n}}$ values, and relative reduced widths have been measured of riany ${ }^{33} \mathrm{~S}$ levels up to $E_{\mathrm{x}}=7.45 \mathrm{MeV}^{20}$.

${ }^{36} \mathrm{Ar}(\mathrm{n}, x)^{33 \mathrm{~S}}$

The thermal cross section is $235 \pm 5 \mathrm{mb}^{32}$.

${ }^{32} \mathrm{~S}\left(\mathrm{p}, \mathrm{p}^{\prime}\right)^{32} \mathrm{~S}$

${ }^{33} \mathrm{Cl}$

Broad resonances in the yield of $E_{\gamma}=2.24 \mathrm{MeV}$ have been observed at $E_{\mathrm{p}}=4.8,5.1,(5.3)$, and $(5.6) \mathrm{MeV}^{35}$.

$31 \mathrm{P}(x, \mathrm{p})^{3 A} \mathrm{~S}$

$34 S$

At $E_{2}=42 \mathrm{MeV}, \sigma(\vartheta)$ of groups $\mathrm{p}_{0}$ and $\mathrm{p}_{1}$ has been measured ${ }^{43}$.

${ }^{33} \mathrm{~S}(\mathrm{~d}, \mathrm{p})^{34} \mathrm{~S}$

The final text of the paper quoted as $\mathrm{Br} 61 \mathrm{e}$ contains several small changes in excitation energies; the levels at (4.26), (5.85), 7.78, 7.914, and (8.12) $\mathrm{MeV}$ have been dropped; new levels are found at $6.690,6.959,(7.398), 7.750$, and $7.783 \mathrm{MeV}^{11}$.

${ }^{34} \mathrm{~S}\left(\mathrm{p}, \mathrm{p}^{\prime}\right)^{34} \mathrm{~S}$

Several $\gamma$ transitions have been observed following inelastic proton scattering ${ }^{35}$. ${ }^{3 A} \mathrm{Cl}(\beta+)^{3 A S} \mathrm{~S}$

${ }^{34} \mathrm{Cl}$

The half-life has been measured as $1.56 \pm 0.014 \mathrm{sec}^{37}$.

$3 / \mathrm{S}(\mathrm{d}, \mathrm{p})^{35 \mathrm{~S}}$

${ }^{35} \mathrm{~S}$

${ }^{B} \in E_{d}=8.9 \mathrm{MeV}$, an angular distribution measurement of $\mathrm{p}_{0}$ yields $l_{\mathrm{n}}=2$; cne reduced width is 0.91 times that of ${ }^{32} \mathrm{~S}(\mathrm{~d}, \mathrm{p})^{33} \mathrm{~S}(0)^{20}$.

${ }^{35} \mathrm{Cl}(y, y)^{35} \mathrm{Cl}$

${ }^{35} \mathrm{Cl}$

From bremsstrahlung resonance fiuorescence the mean lives of the 1.76 , 2.65 , and $3.01 \mathrm{MeV}$ levels have been found". 8 . 
${ }^{40} \mathrm{Ar}(\gamma, a)^{36 \mathrm{~S}}$

${ }^{36} \mathrm{~S}$

At $E_{\gamma \max }=70 \mathrm{MeV}$, the $\alpha$-particle energy distribution hat ben manumel and compared with statistical theory calculations ${ }^{\text {in. }}$.

$\left.{ }^{32 \mathrm{~S}}(\alpha, \gamma)\right)^{36 \mathrm{Ar}}$

${ }^{36} \mathrm{Ar}$

In the energy range $E_{x}=2.2-3.2 \mathrm{MeV}$, resonances have been fommd at $E_{x}=2.550\left(J^{\pi}=2^{+}\right), 2.785\left(J^{\pi}=1-\right), 3.056\left(J^{r}=2 \cdot\right)$, and $3.182 \mathrm{Mel}$, all $\pm 0.005 \mathrm{MeV}^{99}$.

${ }^{35} \mathrm{Cl}(\mathrm{p}, \gamma)^{36} \mathrm{Ar}$

New resonances have been found at $E_{\mathrm{p}}=624,87.3$ and $986 \mathrm{keV}$, all $\pm 1 . j$ $\mathrm{keV}^{99}$. Precision measurements of resonance energies yield $E_{\mathrm{p}}=4.11 .1 .0 .5$. $532.9 \pm 0.6,575.2 \pm 0.6,643.2 \pm 0.7$, and $656.0+0.7 \mathrm{kcl} ! \mathrm{k}$.

${ }^{37} \mathrm{Ar}(\mathrm{EC}){ }^{37} \mathrm{Cl}$

${ }^{37} \mathrm{Ar}$

The $\mathrm{L} / \mathrm{K}$ capture ratio has been measured as $(9.71 \div 0.05) \times 10^{-2} 4^{4}$.

${ }^{36} \mathrm{Ar}(\mathrm{n}, \mathrm{n}){ }^{36} \mathrm{Ar}$

Analysis of the scattering cross section measured in the $E_{\mathrm{n}}=\left(0 . \mathrm{i}-(\mathbf{i}) \times 10^{3}\right.$ $\mathrm{eV}$ range, yields a iesonance at $E_{n}=-9.8 \mathrm{keV}$, with $l_{n}=82 \mathrm{eV}$, and $\Gamma_{.}=1.85 \mathrm{eV}^{19}$.

${ }^{36} \mathrm{Ar}(\mathrm{p}, \mathrm{p}){ }^{36} \mathrm{Ar}$

${ }^{37} \mathrm{~K}$

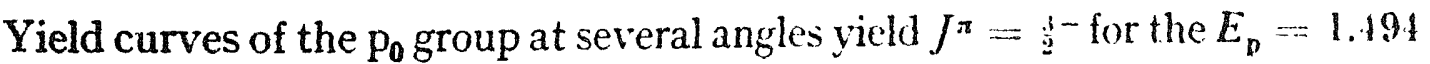
$\mathrm{MeV}$ resonance, correspondirg to the $3.44 \mathrm{MeV}$ level in ${ }^{37} \mathrm{~K}^{38}$. This reference replaces $\mathrm{Ki} 61 \mathrm{a}$.

\section{${ }^{38} \mathrm{Ar}$}

${ }^{34} \mathrm{~S}(\alpha, \gamma){ }^{38} \mathrm{Ar}$

With enriched ${ }^{34} \mathrm{~S}$ targets, resonances have been found at $E=2.060$, z.772, 2.911, 3.025, 3.116, and 3.161 M.T, all :0.005 MeV. All six resonance levels have $J^{\pi}=1^{-99}$.

${ }^{37} \mathrm{Cl}(\mathrm{p}, \gamma){ }^{38} \mathrm{Ar}$

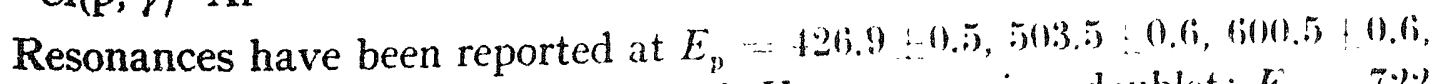
$624.2 \pm 0.7,690.1 \pm 0.7 \mathrm{keV}^{98}$. The $72 \mathrm{t} \mathrm{keV}$ resonance is a doublet: $E_{0}$. 72.2 and $725 \mathrm{keV}$, both $\pm 1.5 \mathrm{keV}^{99}$.

${ }^{37} \mathrm{Cl}(\mathrm{p}, \mathrm{n}){ }^{37} \mathrm{Ar}$

Yield curves of the $n_{0}$ and $n_{1}$ groups show many resonances in the $E_{p} \cdots 1.5$. $4.0 \mathrm{MeV}$ region ${ }^{5}, 47$. These references replace Ba dile and ila 61. 
${ }^{38} \mathrm{~K}^{\mathrm{m}}\left(\beta^{+}\right)^{38} \mathrm{Ar}$

38K

The half-life has been measured as $0.948 \pm 0.010 \mathrm{sec}$, the $\beta^{+}$end point is $5.00 \pm 0.07 \mathrm{MeV}^{37}$. This reference replaces $\mathrm{Ju} 61$.

${ }^{40} \mathrm{Ca}(\mathrm{n}, \mathrm{t})^{38 \mathrm{~K}}$
At $E_{\mathrm{m}}=14.7 \mathrm{MeV}, \sigma \leqslant 0.1 \mathrm{mb}^{96}$.

${ }^{39} \mathrm{~K}(\gamma, \gamma)^{39} \mathrm{~K}$

39K

A yield curve of resonantly scattered bremsstrahlung with an energy between $E_{\max }$ and $E_{\max }-1 \mathrm{MeV}$ shows a peak at $7.0 \mathrm{MeV}^{74}$. From the same reaction the mean lives of the 3.02 and $3.88 \mathrm{MeV}$ levels have been found?

$$
{ }^{40} \mathrm{Ar}\left(\mathrm{p}, \mathrm{p}^{\prime}\right)^{40} \mathrm{Ar}
$$

${ }^{40} \mathrm{Ar}$

At $E_{\mathrm{p}}=7.3$ and $9.4 \mathrm{MeV}$, inelastic scattering has been observed, exciting $\therefore 2{ }^{40} \mathrm{Ar}$ levels, up to $E_{\mathrm{x}}=6.65 \mathrm{MeV}^{6}$. At $E_{\mathrm{p}}=8 \mathrm{MeV}$, the azimuthal asymmetry of elastically scattered polarized protons has been measured ${ }^{64}$.

$$
{ }^{39} \mathrm{~K}(\mathrm{p}, y){ }^{40} \mathrm{Ca}
$$

${ }^{40} \mathrm{Ca}$

From branchings, yield, and angular distribution measurements, $J=1$ and $2+$ has been assigned to the $E_{\mathrm{p}}=1575.5$ and $1580 \mathrm{keV}$ resonances, respectively ${ }^{66}$. A resonant absorption measurement of $\gamma_{0}$ at the lower resonance yields the total and radiation width ${ }^{63}$. Reson nces have been reported at $E_{\mathrm{p}}=1.106$, $1.133,1.241,1.309,1.310,1.315,1.348,1.579,1.583$, and $2.045 \mathrm{MeV}$, all \pm 0.003 $\mathrm{MeV}$, and at $E_{\mathrm{p}}=1.475 \pm 0.010 \mathrm{MeV}$. The decay of the resonance levels proceeds partly through new levels at $7.00,7.49,7.88,8.48$, and $9.06 \mathrm{MeV}$, all $+0.02 \mathrm{MeV}^{100}$.

$$
{ }^{40} \mathrm{Ca}(\gamma, y)^{40} \mathrm{Ca}
$$

The yield curve of resonantly scattered bremsstrahlung shows a giant resonance with a maximum at $20.5 \mathrm{MeV}$; the angular distribution is consistent with dirule scattering ${ }^{13}$. The yield curve of resonantly scattered bremsstrahlung witr energies between $E_{\max }$ and $E_{\max }-1 \mathrm{MeV}$ shows a peak at $8.0 \mathrm{MeV}^{74}$.

${ }^{40} \mathrm{Ca}\left(c, e^{\prime}\right)^{40} \mathrm{Ca}$

At $E_{e}=120,150$, and $180 \mathrm{MeV}$, inelastically scattered eleciron groups have been observed corresponding to levels at $3.8, \approx 6.5,15.2,17,18,19.2$, 20.5, and $40-45 \mathrm{MeV}^{60}$. 
${ }^{40} \mathrm{Ca}\left(\mathrm{p}, \mathrm{p}^{\prime}\right)^{40} \mathrm{Ca}$

The azimuthal asymmetry in elastic scattering of polarized $\times$ Me i protin: has been measured 64 . The probability of two-photon de-excitation (f 4 (a) compared to pair formation is less than $0.7 \%{ }^{27}$.

REMARISS

Yield curves and angular distributions have been computed for til. (i, in) and $(\gamma, p)$ reactions on ${ }^{40} \mathrm{Ca}^{3}$.

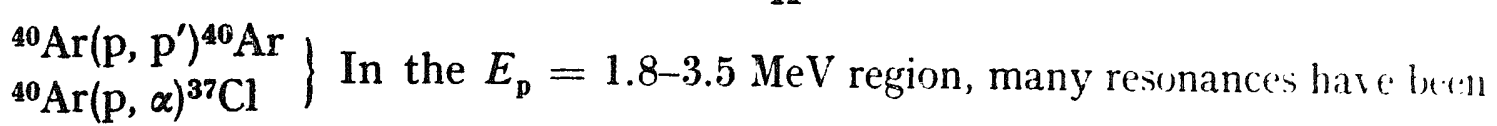
observed in the yield of the $\mathrm{p}_{0}, \mathrm{p}_{1}$, and $\alpha_{0}$ groups. This reference replaces $\mathrm{Ba} 60 \mathrm{~d}$. For proton elastic scattering, see also ref. ${ }^{18}$.

${ }^{42} \mathrm{~K}$

${ }^{42} \mathrm{~K}\left(\beta^{-}\right)^{42} \mathrm{Ca}$

The $\beta-\gamma\left(\mathrm{E}_{y}=1.52 \mathrm{MeV}\right)$ circular polarization correlation has been measured $^{21}$.

\section{${ }^{42} \mathrm{Ca}$}

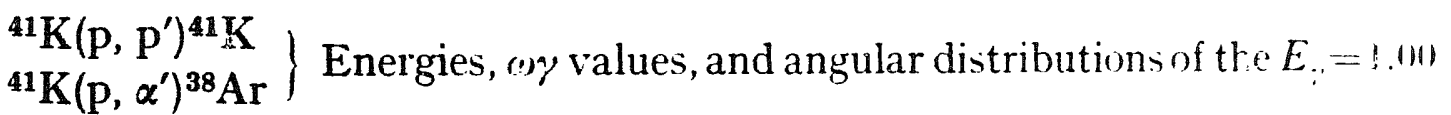
and $2.16 \mathrm{MeV} \gamma$ rays have been measured in the $E_{\mathrm{p}}=2.3-3.4 . \mathrm{Mel}^{*}$ region ${ }^{67}$. This reference replaces Sh $58 \mathrm{c}$, Sh $59 \mathrm{a}$, Sh 61.

$$
{ }^{42} \mathrm{Sc}\left(\beta^{+}\right){ }^{42} \mathrm{Ca}
$$

The half-life has been measured as $0.69 \pm 0.110$ sec: the fi-d point is $5.32 \pm 0.10 \mathrm{MeV}^{3}$ ? This reference replaces Ju fil. For a theoretical discur-ion of the lowest $T=0$ and $T=1$ levels, and the expected ipm enentence. rete reference ${ }^{101}$.

$$
{ }^{43} \mathrm{Sc}\left(\beta^{+}\right){ }^{43} \mathrm{Ca}
$$

\section{${ }^{43} \mathrm{Ca}$}

A theoretical discussion is given of the ft ralute ${ }^{21}$.

45K

${ }^{45} \mathrm{~K}\left(\beta^{-}\right)^{45} \mathrm{Ca}$

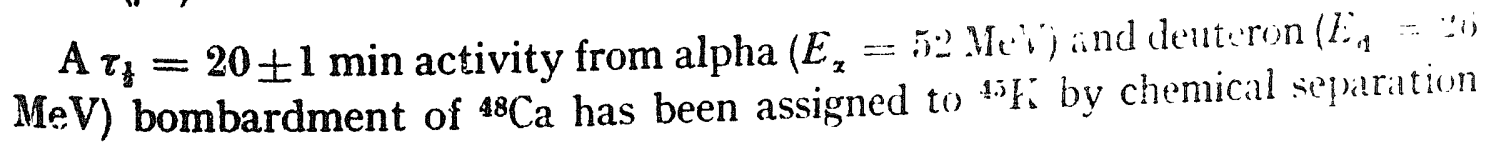


and measurement of the $\gamma$-ray energies. Coincidence of the strongest $\gamma$ rays $\left(E_{. j}=0.175\right.$ and $\left.1.71 \pm 0.02 \mathrm{MeV}\right)$ suggests a $1.902 \rightarrow 0.170 \rightarrow 0$ cascade. The most intensive $\beta$ - component, probably proceeding to ${ }^{45} \mathrm{Ca}^{*}=1.902 \mathrm{MeV}$, has an end point of about $2 \mathrm{MeV}$, yielding a ${ }^{45} \mathrm{~K}$ mass excess of $-37 \mathrm{MeV}$. The allowed character of this $\beta^{-}$transition $(\log f t=5.4 \pm 0.2)$ would imply an unexpected odd parity for the ${ }^{45} \mathrm{~K}$ ground state ${ }^{103}$.

$\therefore \mathrm{Ca}(\beta-)^{45} \mathrm{Sc}$

45 Ca

theoretical discussion is given of the value 41 .

${ }^{4} \mathrm{Ca}(\mathrm{d}, \mathrm{p})^{45} \mathrm{Ca}$

The polarization of the $p_{0}$ group is computed from D.W.B.A. analysis ${ }^{14}$.

${ }^{4.5} \mathrm{Sc}(\mathrm{n}, \mathrm{p})^{45} \mathrm{Ca}$

The cross section has been measured for fission neutrons ${ }^{40}$.

\section{References Addenda}

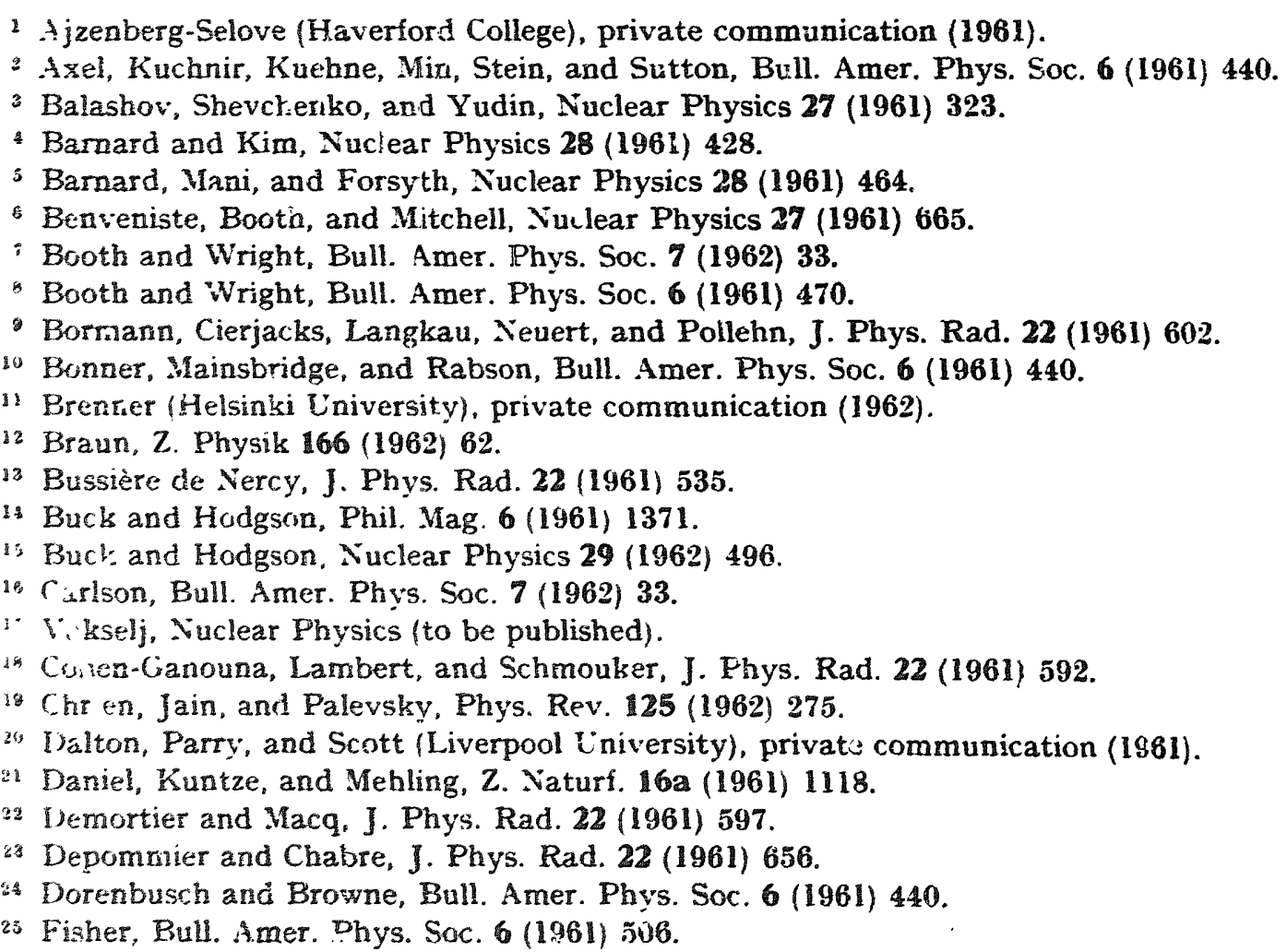


26 Glasgow and Schecter, Phys. Rev. 123 (1961) 2149.

27 Gorodetzky, Sutter, Armbruster, Chevallier, Ivennrath, Scheibling, and Yoccoz, J. Phys.
Rad. 22 (1961) 688.

28 Harvey and Elliott, Bull. Amer. Phys. Soc. 7 (1962) 19.

28 Grüebler and Rossel, Helv. Phys. Acta 34 (1961) 718.

30 Gustafson, Nuclear Physics 28 (1961) 665.

31 Harris and Seagondollar, Bull. Amer. Phys. Soc. 6 (1961) 440.

s2 Hanna, Primeau, and Tunnicliffe, Canadian J. Phys. 39 (1\%61) 1784

33 Heinrich and Tanner, Helv. Phys. Acta 34 (1961) 481 (A).

34 Hennecke, M.I.T., Laboratory for Nuclear Science Progress Report, May 1 (1961) 129.

35 Hirao, J. Phys. Soc. Japan 16 (1961) 1828.

36 Iyengar and Peck (Brown University, Rhode Island), private communication (1961).

37 Jänecke and Jung, Z. Physik 165 (1961) 94.

38 Kim and Barnard, Nuclear Physics 28 (196i) 438.

39 Kokame, J. Phys. Soc. Japan 16 (1961) 2101.

40 Münze, Jantsch, and Hladik, Kernenergie 4 (1961) 293.

41 Lawson, Phys. Rev. 124 (1961) 1500.

42 Lane, Elwyn, and Langsdorf, Bull. Amer. Phys. Soc. 6 (1961) 430.

43 Lieber and Schmidt, Univ. of Washington, Cyclotron Fiesearch, Annual Progress Report 1961, p. 38.

44 Józefowicz, Nukleonika 6 (1961) 379.

45 Matsuda, Nagahara, Oda, Yarnamuro, and Kobayashi, Nuclear Hhysics 27 (1961) 1.

\$3 Martin and Marmier, Helv. Phys. Acta 34 (1961) $484(A$,

47 Mani, Barnard, Tombrello, and Rao, Nuclear Physics 28 (1!61) 456.

48 Misuda, J. Phys. Soc. Japan 16 (1961) 1801.

18 Manduchi and Zannoni, Nuovo Cimento 22 (1951) 46 .

50 Mouton, Sellschop, and Keddy (Lniversity of the Witwatersrand, Johannesburg), private communication.

51 Naqib, Univ. of Washington, Cyclotron Research, Annual Progress Report 1!361, p. j.

52 Wong, Anderson, McClure, and Walker, Bull. Amer. Phys. Soc 7 (1!962) $4 \%$

53 Neudachin and Orlin, Zh. Eksp. Teor. Fiz. 41 (1961) 874.

54 Stuart, Anderson, and Wong, Phys. Rev. 125 (1962) 276.

53 Newman (Brookhaven), private communication to Nuclear l)ata I'roject (1961).

56 Nelson, Carlson, and Schlenker, Nuclear Physics (to be published).

57 Neher, Prosser, and Krone, Nuclear Physsics (to be published).

58 Neudachin and Orlin, Nuclear Physics (to be published).

50 Ophel and Lawergren, Nuclear Physics 30 (1962) 215.

60 Perez y Jorba and Nguyen Ngoc, J. Phys Rad. 22 (19131) isi.

61 Prosser, Unruh, Wildenthal, and Krone, l'hys. Rev 125 (1962) 594.

${ }_{62}$ Pucherov, Ukrayin. fiz. Zh. 4 (1959) 3 I3.

*3 Rangan, Harris, and Seagondollar, Bull. Amer. Ihys. Sox. $6(1961)+4$.

64 Rosen, Brolley, Gursky, and Stewart, Phys. R.. 124 (1961) 1:39.

85 Robson, Nuclear Physics 30 (1962) 316.

o6 Seagondollar, Rangan, Moore, and Harris, Buli. Imer. I'hys Sox. 6 il!ntili $4+1$

67 Sharp, Chase, Friedman, Warburton, and Shelley, lhys. Rer. 124 (1!*il) 1.5.5.

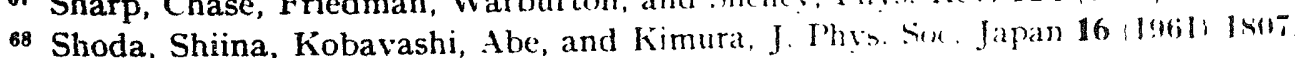

69 Sheline and Harlan, Nuclear Physics 29 (I91:2) 17T.

70 Strizhak, Bobyr, and Grona, Zh. Eksp. Tor. Fiz. 11 (l96i) 3 J3.

is Sugawara, J. Phys. Soc. Japan 16 (1961) 1 $x, 1 \%$.

32 Sytenkn and Kharchenko, Ukravin. fiz. Zh. $4(1 ! 9,19)$, wi!l

73 Takano, J. Phys. Soc. Japan 16 (1961) 5!1\%.

is Tohei, Sugawara, Mori, and Kimura, J. Phys. Skx. Japan 16 (1!16il) 16isi.

75 Tutakin, Izvest. Akad. Nauk, Ser. Fiz. 25 (1941) 1131.

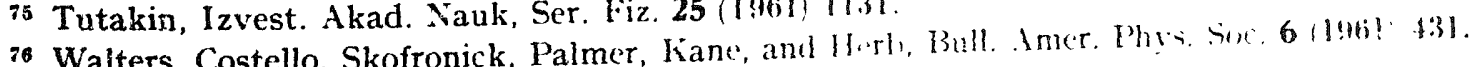

7 Warsh, Blieden, and Temmer, Bull. Amer Phys. S̈" 6 (13:6il) 40 .

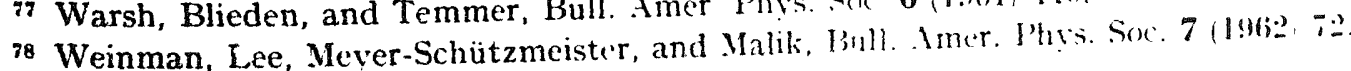


"Y Yamaguchi, J. Phys. Soc. Japan 16 (1961) 583.

80 Kuehner, Litherland, Almovist, and Evans, Bull. Amer. Phys. Soc. 7 (1962) 73.

81 Murray, Graham, and Geiger, Bull. Amer. Phys. Soc. 7 (1962) 72.

82 Naquib, Bull. Amer. Phys. Soc. 7 (1962) 73.

33 Willard and Bair, Bull. Amer. Phys. Soc. 7 (1962) 73.

is Bishop and Proca, J. Phys. Rad. 22 (1961) 541.

8 i Valerio and Nelson, Nuclear Physics 29 (1962) 70.

${ }^{8 \epsilon}$ Sukhanov and Rukavishnikov, Atomnaya Energiya 11 (1961) 398 (L).

$\varepsilon_{i}$ Griffy and Biedenharn, Nuclear Physics (to be published).

${ }^{88}$ Smulders (Utrecht University), private communication (1962).

${ }^{8 s}$ Makhnovsky, Zh. Eksp. Teor. Fiz. 41 (1961) 1091.

90 Coleman and Perkin, Proc. Phys. Soc. 78 (1961) 1163.

91 Degtyarev and Nadtochii, Atomnaya Energiya 11 (1961) 397 (L).

92 Berzin and Meshcheryakov, Zh. Eksp. Teor. Fiz. $\$ 1$ (1961) 1013.

23 Bashkin and Ophel, Australian J. Phys. 14 (1961) 335.

ga Brenner, Hoogenvoom, and Kashy, Phys. Rev. (to be published).

${ }_{95}$ Zaika and Nemets, Izvest. Akad. Nauk, Ser. Fiz. 25 (1961) 1308.

${ }_{36}$ Weigold and Glove:, Nuclear Physics (to be published).

g7 Valter, Antuniev, Kopanets, Lvov, and Tsytko, Zh. Eksp. Teor. Fiz. 41 (1961) 1449.

48 Heitzmann and Wagner, $Z$. Naturf. 16 a (1961) 1136.

89 Van der Leun and Erné (Utrecht University), private communication (1962).

100 Leenhouts (Utrecht University), private communication (1962).

101 Jänecke, Nuclear Physics 30 (1962) 328.

102 Jaidar, Lopez, Mazan, and Dominguez, Revista Mexicana de Fisica 10 (1961) 247.

103 Morinaga (Tokyo University), private communication (1962).

109 Zyrianova and Pantiushin, Izvest. Akad. Nauk, Ser. Fiz. 26 (1962) 150.

${ }_{105}$ Komar, Bochagov, and Soliakin, Dokl. Akad. Nauk 141 (1961) 1339.

${ }_{106}$ MacDonald, Nuclear Physics (to be published).

10: Baart, Green, and Willmott, Proc. Phys. Soc. 79 (1962) 237.

108 Nillsson, Saw shi, and Glendenning, Nuclear Physics (to be published). 